\title{
Evaluation of Antioxidant Activities of Some Small Fruits Containing Anthocyanins Using Electrochemical and Chemical Methods
}

\author{
Adina Căta, ${ }^{1}$ Mariana N. Ştefănuț, ${ }^{1, *}$ Raluca Pop,${ }^{2}$ Cristian Tănasie, ${ }^{1}$ Cristina Moşoarcă, ${ }^{1}$ Alina D. Zamfir ${ }^{1,3}$
}

\footnotetext{
1 National Institute of Research and Development for Electrochemistry and Condensed Matter, Dr. Aurel Păunescu Podeanu 144, 300569, Timişoara, Romania

2 University of Medicine and Pharmacy, Eftimie Murgu Square 2, 300041, Timişoara, Romania

3 Department of Chemical and Biological Sciences, "Aurel Vlaicu” University of Arad, Revoluţiei Blvd. 77, 310130, Arad, Romania

* Corresponding author's e-mail address: mariana.stefanut@gmail.com
}

RECEIVED: May 5, 2015 * REVISED: August 28, 2015 * ACCEPTED: January 18, 2016

\begin{abstract}
The objective of this work was to estimate the antioxidant capacity of some fruits extracts containing anthocyanins (strawberry, raspberry, elderberry, mulberry, blackberry, bilberry, black and red currant) using an electrochemical technique and three classical chemical methods based on reaction between antioxidants and a chromogen compound. evaluation of antioxidant activities of extracts was performed by using FRAP (ferric reducing/antioxidant capacity), ABTS (2,2'-azinobis[3-ethylbenzothiazoline-6-sulphonate]) and DPPH (2,2-diphenyl-1picrylhydrazyl) assays. Antioxidant activities of the extracts were correlated with their content of monomeric anthocyanins and total phenolics. Good correlations were obtained especially between antioxidant activities and total phenolics content. Cyclic voltammetry was used for the evaluation of overall reducing capacity of the extracts using a glassy carbon electrode. Reducing capacity of selected fruits extracts was assessed based on the half-peak potential $\left(E_{1 / 2}\right)$ of the first oxidation peak. The oxidation potentials characterized by $E_{1 / 2}$ value were not correlated with the antioxidant activities evaluated by the classical methods.
\end{abstract}

Keywords: anthocyanins, total phenolics, antioxidant activity, cyclic voltammetry.

\section{INTRODUCTION}

A nthocyanins are water-soluble pigments that belong to the flavonoids group and are responsible for the red-bluish coloration from the vegetal world. ${ }^{[1]}$ Anthocyanins are encountered as individuals or mixture of six most common anthocyanidins (cyanidin, delphinidin, pelargonidin, peonidin, petunidin, malvidin) substituted usually in 3 or 3,5 position of $A$ and $C$ rings with different sugars such as glucose, galactose, rhamnose, arabinose or xylose. Acylation of sugar groups with various aliphatic and aromatic acids contribute to the wide variety of anthocyanin compounds found in nature. The most widespread anthocyanin is cyanidin-3-glucoside. ${ }^{[2,3]}$ There is a continuous interest regarding the use of anthocyanins in both food and nutraceutical industry. Besides their use as natural pigments in food industry, they also could have applications in medicine, in treatment of diabetes, ${ }^{[4,5]}$ eyesight disorders ${ }^{[5]}$ or coronary diseases. ${ }^{[6-8]}$ These properties are mostly due to their antioxidative action as free radical scavengers, but mechanisms like metal chelation and protein binding also play an important role. ${ }^{[9]}$

Anthocyanins are part of the human diet by consumption of fruits and vegetables both fresh and processed form. There are many methods that are used for the analysis and characterization of anthocyanins. For quantitative information regarding the anthocyanins content in crude extracts containing other phenolic compounds, the spectroscopy is the main technique used due to its simplicity and low cost. ${ }^{[10]}$ Identification of individual anthocyanins is quite complicated due to the variability in the patterns of these pigments as function of plant species and also due to the lack of standards for many of them. The most used technique for separation, identification and quantification of anthocyanins is high performance liquid chromatography (HPLC) coupled with UV-Vis, photodiode array (PDA) or mass spectrometry (MS) detectors. ${ }^{[11-14]}$ Small berry fruits like chokeberry, elderberries, blackcurrants, bilberry, etc. 
are very rich sources of anthocyanins and other phenolic compounds like flavonols, hydroxycinnamic acids, ellagitannins, procyanidins. ${ }^{[15-17]}$ As a consequence, their antioxidant capacity will depend on the synergic and redox interactions among these constituents and with other compounds that are present in the food. ${ }^{[18]}$ There is no universal method to be used for the evaluation of the antioxidant capacity. According to Huang et al., ${ }^{[19]}$ the antioxidant activity of a compound (or extracts, various solutions) strictly refers to some characteristic reaction conditions and, consequently, will reflect the chemical reactivity in that specific assay.

It is well known that the antioxidant properties of the anthocyanins are due to the scavenging of free radicals by means of their hydroxyl groups. There are two main mechanisms that describe the antioxidant properties of the phenolic compounds, namely HAT - hydrogen atom transfer and SET - single electron transfer. ${ }^{[20]}$ As a function of the involved mechanism, the methods for determining the antioxidant capacity can be classified as methods based on HAT mechanism (ORAC, TRAP) or methods based on SET mechanism (FRAP, DPPH, ABTS (TEAC)); the main difference is that former evaluates the hydrogen atom transfer reaction, while the latter quantify the reducing activity of an antioxidant. ${ }^{[19]}$ Specific for the SET-based assays is the use of an oxidant (e.g. FRAP, ABTS, DPPH reagent) that withdraws an electron from the considered antioxidant and determines a colorimetric change of the reaction mixture. ${ }^{[19]}$

Taking into account that the radicals scavenge is an electron-transfer reaction, electrochemical methods may be used in order to evaluate the antioxidant behavior of the anthocyanins. Unlike these chemical methods that use a large number of oxidizing agents for determining the antioxidant character, the electrochemical oxidation has the advantage of previous established working conditions (e.g. a certain potential at which the oxidation reaction will occur). ${ }^{[21]}$ It is also well-known that the oxidation potential is inversely related to the electrochemical potential (higher antioxidant activity corresponds to lower potentials). [21-23] Among the electrochemical techniques, cyclic voltammetry is the most used for evaluation of the overall reducing capacity of phenolics from various plant samples ${ }^{[24-26]}$ or wines. ${ }^{[27,28]}$ However, this technique is not widely used compared to conventional methods such as DPPH, ABTS, etc.

In a previous study, we characterized anthocyanins in four indigenous wild berries which are important sources of anthocyanins in the diet. This work extended the range of studied fruits with several Romanian species of both wild and cultivated fruits (strawberry, raspberry, elderberry, mulberry, blackberry, bilberry, black and red currant) and started their investigation by developing new HPLC methods more suitable for anthocyanins separation. Also, the most important objective of this study was the in vitro evaluation of antioxidant capacities of the selected fruits and the correlation of antioxidant capacities with the content of monomeric anthocyanins and total phenolics. Because of the differences between reaction mechanisms of different assays, a single assay will not reflect all the antioxidants presents in a vegetal sample, therefore four methods were used for appreciation of antioxidant activities: an electrochemical one, cyclic voltammetry, a simple and rapid electrochemical technique for assessing the overall reducing capacity of natural antioxidants expressed as TERP (total electrochemical reducing power) and three SETbased chemical assays, namely FRAP, DPPH and ABTS. Finally, real correlation between total electrochemical reducing power and antioxidant activities assessed by conventional methods was established.

\section{EXPERIMENTAL}

\section{Reagents and Materials}

Cyandin-3-glucoside, cyandin-3-rutinoside, malvidin-3-glucoside, malvidin-3-galactoside, pelargonidin-3-glucoside, delphinidin, cyanidin and malvidin chlorides, trifluoroacetic acid, methanol (HPLC grade), Folin-Ciocalteu reagent, 1,1diphenyl-dipicrylhydrazyl (DPPH), gallic acid and 6-hidroxy2,5,7,8-tetramethylchromane-2-carboxylic acid $97 \%$ (Trolox) were purchased from Sigma-Aldrich, Germany. Iron (III) chloride, 2,4,6-tris(2-pyridyl-1,3,5-triazine (TPTZ) and 2,2'azino-bis(3-ethylbenzthiazoline-6-sulphonic acid) (ABTS) were purchased from Sigma, Germany. Hydrochloric acid was obtained from Merck, Germany. Ultrapure water for chromatographic analysis was produced by an EASYpure ${ }^{\circledR}$ RoDi Barnstead system (USA) for laboratory water purification.

Eight species of berries from different botanical families, native to Romania were selected for this study. Four wild berries i.e. elderberry (Sambucus nigra L.), black mulberry (Morus nigra L.), blackberry (Rubus fruticosus L.) and bilberry (Vaccinium myrtillus L.) were harvested from wild and unpolluted areas of south western Romania $\left(45^{\circ} 22^{\prime} 02^{\prime \prime} \mathrm{N}\right.$ and $22^{\circ} 21^{\prime} 07^{\prime \prime} \mathrm{E}$ and $420 \mathrm{~m}$ altitude) at the maturity stage. Strawberry (Fragaria $\times$ ananassa), raspberry (Rubus idaeus L.), black currant (Ribes nigrum L.) and red currant (Ribes rubrum L.) were purchased from local farms (45 $39^{\circ} 06^{\prime \prime} \mathrm{N}$ and $21^{\circ} 10^{\prime} 01^{\prime \prime} \mathrm{E}$ and $80-90 \mathrm{~m}$ altitude, no pesticides as contaminants). All fruits were collected in 2011 in the summer months (June-August).

\section{Sample Preparation}

An ultrasound assisted extraction procedure was used in this work. $25 \mathrm{~g}$ fresh fruits were crushed, weighed and 
extracted with $0.1 \%$ hydrochloric acid in methanol at solid to solvent ratio $1: 4(w / v)$ for $1 \mathrm{~h}$ at $25 \pm 2{ }^{\circ} \mathrm{C}$ and $59 \mathrm{kHz}$ using an ultrasonic bath (LBS 2, FALC Instruments, Italy). The extracts were filtered through a Whatman no. 1 filter paper, and then the solvent was removed in a rotary evaporator (Laborota 4000 Efficient, Heidolph, Germany) under vacuum at $35-40^{\circ} \mathrm{C}$ until a volume of $14-15 \mathrm{~mL}$. For an accurate comparative analysis of the extracts, they were brought to the same volume with methanol $(20 \mathrm{~mL})$. Before each type of determination, the samples were centrifuged at 2000×g for 20 min using a mini centrifuge Labnet C1301 (Labnet International, Korea).

\section{Determination of Total Anthocyanin Content (TAC)}

Total monomeric anthocyanins content (TAC) was quantified using a $\mathrm{pH}$ differential method described by Giusti \& Wrolstad.[29] The samples were appropriately diluted in potassium chloride buffer $(\mathrm{pH} 1.0)$ and sodium acetate buffer ( $\mathrm{pH} 4.5)$ and then the absorbance was measured simultaneously at $\lambda_{\text {vis-max }}(500-520 \mathrm{~nm})$ and $700 \mathrm{~nm}$ using a Jasco V 530 UV-Vis spectrophotometer. Each sample was analyzed in triplicate. The total monomeric anthocyanins content was expressed as cyanidin-3-glucoside equivalents ( $\mathrm{MW}=449.2$ and $\varepsilon=26900$ ) in $\mathrm{mg}$ of anthocyanin/liter of fruit extract.

\section{Determination of Total Phenolic Content (TPC)}

The total phenolics content (TPC) of the extracts was determined by using the Folin-Ciocalteu method ${ }^{[30]}$ and gallic acid as standard. After incubation for 2 hours at room temperature, the absorbance at $765 \mathrm{~nm}$ was determined using a Jasco V 530 UV-Vis spectrophotometer. The calibration curve of gallic acid was obtained using 10 standard solutions in the range $50-550 \mathrm{mg} \mathrm{L}^{-1}$. Total phenolics content of the extracts were expressed as $\mathrm{mg}$ gallic acid equivalents per liter of fruit extract ( $m g G A E L^{-1}$ ). All samples were analyzed in triplicate.

\section{Anthocyanins Identification}

A chromatographic system Dionex Ultimate 3000 apparatus (Dionex Corporation, USA) equipped with a LPG 3400A quaternary pump, PDA 3000 photodiode array detector, a $20 \mu \mathrm{L}$ injection loop and a $4.6 \times 150 \mathrm{~mm}, 5 \mu \mathrm{m} \mathrm{C}-18$ Acclaim $^{\circledR} 120$ Silica-Based reversed-phase column (Dionex Corporation) was used for anthocyanins detection. Chromatograms were recorded and processed with Chromeleon 6.8 Software. The column was maintained at $40{ }^{\circ} \mathrm{C}$ using a thermostated column compartment Dionex TCC- 3000 .

For HPLC analysis of anthocyanins fruit extracts were diluted in $0.5 \%$ trifluoroacetic acid (TFA) and filtered through a $0.45 \mu \mathrm{m}$ PTFE syringe filter prior to injection.
Anthocyanins detection was carried out at $520 \mathrm{~nm}$. The chromatographic separations were carried out at in isocratic conditions using as mobile phase aqueous solution of $30 \% \mathrm{MeOH}$ containing $0.5 \%$ TFA at a constant flow rate of $1.0 \mathrm{~mL} \mathrm{~min}-1$., except for elderberry and bilberry extracts. For elderberry extract, was used the same mobile phase in isocratic condition, but at a flow rate of $0.5 \mathrm{~mL} \mathrm{~min} \mathrm{~min}^{-1}$. For analysis of bilberry extract, the same method as in ${ }^{[31]}$ was used: isocratic conditions for 30 minutes with $100 \%$ solvent A (aqueous solution of $20 \% \mathrm{MeOH}$ containing $0.5 \% \mathrm{TFA}$ ), linear gradient conditions from $100 \% \mathrm{~A}$ to $90 \% \mathrm{~A}$ in the next 30 minutes and then isocratic conditions with $90 \% \mathrm{~A}$ and $10 \% \mathrm{~B}(\mathrm{MeOH})$ until the end of analysis at a constant flow rate of $1.5 \mathrm{~mL} \mathrm{~min} \mathrm{~m}^{-1}$.

Due to the lack of many anthocyanin standards, additional structural data were obtained through mass spectrometry analysis. Prior to MS analysis, the berries extracts were 50 -fold diluted with $0.5 \%$ TFA acidified methanol and then vortexed $(3 \mathrm{~min})$ and centrifuged $(20 \mathrm{~min}$, $2000 \times g$ ) at room temperature. Mass spectra were recorded on a high capacity ion trap instrument (HCT MS) from Bruker Daltonics (Germany), in laboratory coupled with the NanoMate robot for automatic infusion of samples by chipelectrospray (NanoMate ${ }^{\mathrm{TM}}$ ) from Advion Biosciences (UK). HCT MS instrument was controlled through the Esquire Control 6.1.512 software and ChipSoft 7.1.1 software was used for the NanoMate robot. Experimental data were processed with Data Analysis 3.4.179 software. Mass spectra were recorded in the positive ion mode within (50-2800) $\mathrm{m}$ $/ z$ range, with a scan speed of $8000 \mathrm{~m} / \mathrm{z}$ per second. The ESI process was initiated by applying $+1.4 \mathrm{kV}$ on the conductive pipette tip of the NanoMate and $-50 \mathrm{~V}$ on the HCT counterelectrode. Nitrogen with a flow rate of $0.5 \mathrm{~L} \mathrm{~min}^{-1}$ was used for desolvation and as a nebulizer gas at $50 \mathrm{psi}$. To enhance the desolvation of the generated ESI droplets, the source block temperature was maintained at $100{ }^{\circ} \mathrm{C}$. The robot was programmed to aspirate $7 \mu \mathrm{L}$ of the sample, followed by $2 \mu \mathrm{L}$ of air into the pipette tip and then inject the sample onto the inlet side of the 400 microchip (each chip nozzle had an internal diameter of $2.5 \mu \mathrm{m}$ ). A new pipette tip and a new nozzle were used for each sample, thus preventing any cross-contamination or carry-over. Tandem mass spectrometry was carried out by collision-induced dissociation (CID) using helium as collision gas with the amplitude of $0.2-0.25 \mathrm{~V}$. The precursor ions for MS/MS sequencing were selected within an isolation width of $2 u$.

\section{Antioxidant Activity}

\section{CYCLIC VOLTAMMETRY}

Electrochemical experiments were carried out with a Voltalab 80 PGZ 402 apparatus from Radiometer Copenhagen, equipped with VoltaMaster 4 software, version 7.0.8, 
using a three-electrode electrochemical cell equipped with working electrode, platinum wire auxiliary electrode and $\mathrm{Ag} / \mathrm{AgCl} / \mathrm{sat}$. $\mathrm{KCl}$ reference electrode. A glassy carbon electrode was used as working electrode. Cyclic voltammograms were recorded at room temperature. Prior to each run, the electrode surface was cleaned by polishing with alumina powder and ultrasonicated 10 minutes in $\mathrm{HCl} 5 \%$. In order to minimize the adsorption of the compounds and their oxidation products onto the electrode surface, the voltammograms were recorded immediately after the immersing of the working electrode in the solution. $\mathrm{NaClO}_{4}$ $0.1 \mathrm{M}$ in methanol $(\mathrm{pH} 3)$ was used as supporting electrolyte. $200 \mu \mathrm{L}$ of each fruits extracts was diluted in $20 \mathrm{~mL}$ background electrolyte for electrochemical tests. A calibration curve was made using standard solutions in the range 0.05-1.0 mmol L-1 Trolox. Taking into account the dilution factor, the area under the anodic curve for all extracts was expressed in terms of mmol Trolox equivalents per liter of fruit extract ( $\mathrm{mmol} \mathrm{L}^{-1}$ Trolox eq.). The areas under curves were automatically calculated by the instrument. All cyclic voltammograms were recorded in duplicate.

\section{DPPH ASSAY}

The free radical scavenging activity of the extracts was performed by using the 1,1-diphenyl-2-picrylhydrazyl (DPPH) assay according to the procedure described by BrandWilliams et al. ${ }^{[32]}$ with some modifications. For this assay, the bilberry and elderberry extracts were forty times diluted and the rest of extracts were twenty times diluted in methanol. Antioxidant solution in methanol $(0.1 \mathrm{~mL})$ was added to $2.9 \mathrm{~mL}$ solution of approximately $0.09 \mathrm{mM} \mathrm{DPPH}$ in methanol. The inhibition of DPPH was followed by monitoring the decrease of absorbance at $515 \mathrm{~nm}$ during 2 hours. Trolox was used as antioxidant reference compound. The calibration curve was obtained using standard solutions in the range $0.2-1.0 \mathrm{mmol} \mathrm{L}^{-1}$ Trolox. Each sample was analyzed in triplicate.

\section{FRAP ASSAY}

The fresh FRAP solution was prepared by mixing $300 \mathrm{mmol} \mathrm{L}^{-1}$ sodium acetate buffer $\mathrm{pH} 3.6$ with $10 \mathrm{mmol} \mathrm{L^{-1 }}$ TPTZ (2,4,6tripyridyl-triazine) in $40 \mathrm{mmol} \mathrm{L}^{-1} \mathrm{HCl}$ and $20 \mathrm{mmol} \mathrm{L}^{-1}$ $\mathrm{FeCl}_{3} \cdot 6 \mathrm{H}_{2} \mathrm{O}$ in double-distilled (dd) water in vol. $10: 1: 1$ ratio. ${ }^{[33]}$ The resulting solution was diluted with 2 volumes of $\mathrm{dd}$ water and was incubated at $37{ }^{\circ} \mathrm{C}$ for 30 minutes. $2.9 \mathrm{~mL}$ of working FRAP solution were mixed with $100 \mu \mathrm{L}$ of extract and was kept in dark for 2 hours, at room temperature. An intense blue colour is formed when the ferric-tripyridyl-triazine complex is reduced to ferrous form. The absorbance of the samples and a blank was measured at $593 \mathrm{~nm}$ against dd water using a Jasco V 530 UV-Vis spectrophotometer. The antioxidant reference compound used was Trolox. Each sample was analyzed in triplicate.

\section{ABTS ASSAY}

ABTS [2,2'-azinobis-(3-ethyl-benzothiazoline-6-sulfonic acid)] radical cation was generated through the reaction between ABTS ( $7 \mathrm{mmol} \mathrm{L}^{-1}$ in $20 \mathrm{mmol} \mathrm{L}^{-1}$ sodium acetate buffer, $\mathrm{pH}$ $4.5)$ and potassium persulfate $\left(2.45 \mathrm{mmol} \mathrm{L}^{-1}\right.$ in same solution). ${ }^{[34]}$ The dark blue-green stable radical solution resulted is incubated $16-18 \mathrm{~h}$, at room temperature, in the dark. The solution was then diluted to an absorbance $1.0 \pm$ 0.02 at $734 \mathrm{~nm}$. The reaction between mixture of $100 \mu \mathrm{L}$ sample and $2.9 \mathrm{~mL}$ ABTS reactive was followed at 734 during 2 hours against dd water. The antioxidant reference compound used was Trolox. Each sample was analyzed in triplicate.

\section{Statistical Analysis}

Statistical analysis was performed using OriginPro 8 software. Data regarding monomeric anthocyanin content, total phenolics content and antioxidant activity of the studied fruits extracts were expressed as the mean \pm standard deviation (SD). The results were processed by using oneway analysis of variance (ANOVA) followed by the Tukey's test. Differences at $p<0.05$ were considered statistically significant. Linear regression analysis was carried out by Matlab Version 7.6.0.324 (R2008a).

\section{RESULTS AND DISCUSSIONS}

All fruit extracts were analyzed by HPLC-DAD and MS in order to identify the main anthocyanins that can contribute to the antioxidant activity of fruits selected for this study. The chromatographic profiles of anthocyanins from eight different crude berries extracts are shown in Figure 1. Several anthocyanins were identified by comparison of their retention times with those of available standards. The other individual anthocyanins, with some exceptions, were tentatively identified in accordance with the elution order of anthocyanins in a reversed phase chromatographic system ${ }^{[12]}$ and previous identification studies and were confirmed by MS analysis (Table 1). A large diversity in anthocyanins composition and proportion of individual anthocyanins was found.

The major anthocyanin in strawberry extract was pelargonidin-3-glucoside ([M] ${ }^{+}$at $\mathrm{m} / \mathrm{z} 433$; peak 4; $77 \%$ of total anthocyanins) followed by pelargonidin-3-rutinoside ([M]+ at $\mathrm{m} / \mathrm{z} 579$; peak 5; $13 \%)$. These results are in agreement with those previously reported by others authors. ${ }^{[35-37]}$ In raspberry extract, the main anthocyanins found were cyanidin-3-sophoroside (peak $1 ; 61.5 \%,[\mathrm{M}]^{+}$at $\mathrm{m} / \mathrm{z} 611$ ), cyanidin-3-glucoside (peak 3; $23 \%$ ) and cyanidin-3-rutinoside (peak $4 ; 13 \%$ ). The presence of these compounds in raspberry extract was also reported by de Ancos et al.,[38] Mullen et al., ${ }^{[39]}$ Chen et al. ${ }^{[40]}$ Six anthocyanins were detected in elderberry extract, the most important components were 


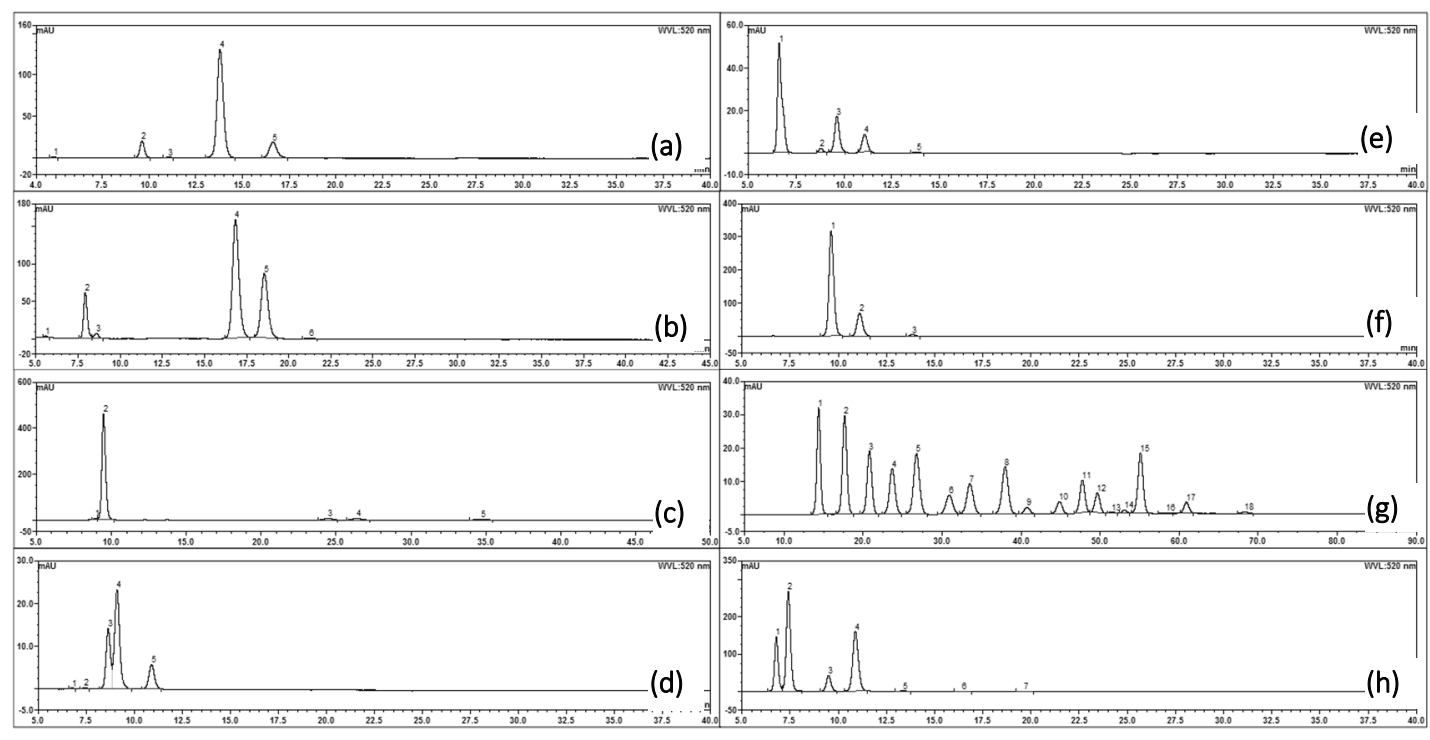

Figure 1. Chromatographic profiles of anthocyanins from studied fruits extracts: (a) strawberry; (b) elderberry; (c) blackberry; (d) red currant; (e) raspberry; (f) mulberry; (g) bilberry; (h) black currant.

Table 1. Identification of anthocyanins form studied fruits extracts.

\begin{tabular}{|c|c|c|c|c|c|}
\hline Peak no. & $\begin{array}{c}\text { Retention time / } \\
\text { min }\end{array}$ & Tentative peak assignment & Total anthocyanins ${ }^{(a)} / \%$ & $\begin{array}{c}\text { Molecular ion }[\mathrm{M}]^{+} \\
(\mathrm{m} / \mathrm{z})\end{array}$ & $\begin{array}{c}\text { Fragment ion } \\
(\mathrm{m} / \mathrm{z})\end{array}$ \\
\hline \multicolumn{6}{|l|}{ Strawberry } \\
\hline 1 & 4.9 & Not identified & 0.4 & - & - \\
\hline 2 & 9.6 & Cyanidin-3-glucoside & 8.7 & 449 & 287 \\
\hline 3 & 11.1 & Cyanidin-3-rutinoside & 0.4 & 595 & 449,287 \\
\hline 4 & 13.8 & Pelargonidin-3-glucoside & 77.1 & 433 & 271 \\
\hline 5 & 16.6 & Pelargonidin-3-rutinoside & 13.4 & 579 & 433,271 \\
\hline \multicolumn{6}{|l|}{ Raspberry } \\
\hline 1 & 6.6 & Cyanidin-3-sophoroside & 61.5 & 611 & 287 \\
\hline 2 & 8.8 & Not identified & 2.4 & - & - \\
\hline 3 & 9.6 & Cyanidin-3-glucoside & 22.6 & 449 & 287 \\
\hline 4 & 11.1 & Cyanidin-3-rutinoside & 12.7 & 595 & 449,287 \\
\hline 5 & 13.8 & Pelargonidin-3-glucoside & 0.8 & 433 & 271 \\
\hline \multicolumn{6}{|l|}{ Elderberry } \\
\hline 1 & 5.6 & Not identified & 0.3 & - & - \\
\hline 2 & 7.9 & $\begin{array}{l}\text { Cyanidin-3-sambubioside-5- } \\
\text { glucoside }\end{array}$ & 12.1 & 743 & $581,449,287$ \\
\hline 3 & 8.6 & Cyanidin-3,5-diglucoside & 1.6 & 611 & 449,287 \\
\hline 4 & 16.8 & Cyanidin-3-sambubioside & 53.9 & 581 & 287 \\
\hline 5 & 18.6 & Cyanidin-3-glucoside & 31.5 & 449 & 287 \\
\hline 6 & 21.3 & Cyanidin-3-rutinoside & 0.6 & 595 & 449,287 \\
\hline \multicolumn{6}{|l|}{ Mulberry } \\
\hline 1 & 9.6 & Cyanidin-3-glucoside & 78.2 & 449 & 287 \\
\hline 2 & 11.1 & Cyanidin-3-rutinoside & 20.2 & 595 & 449,287 \\
\hline 3 & 13.9 & Pelargonidin-3-glucoside & 1.5 & 433 & 271 \\
\hline
\end{tabular}


Table 1 (continued). Identification of anthocyanins form studied fruits extracts.

\begin{tabular}{|c|c|c|c|c|c|}
\hline Peak no. & $\begin{array}{l}\text { Retention time / } \\
\text { min }\end{array}$ & Tentative peak assignment & Total anthocyanins ${ }^{(\mathrm{a})} / \%$ & $\begin{array}{c}\text { Molecular ion }[\mathrm{M}]^{+} \\
(\mathrm{m} / \mathrm{z})\end{array}$ & $\begin{array}{c}\text { Fragment ion } \\
(\mathrm{m} / \mathrm{z})\end{array}$ \\
\hline \multicolumn{6}{|l|}{ Blackberry } \\
\hline 1 & 8.9 & Cyanidin-3-sambubioside & 0.8 & 581 & 287 \\
\hline 2 & 9.5 & Cyanidin-3-glucoside & 90.7 & 449 & 287 \\
\hline 3 & 24.5 & Cyanidin-3-xyloside & 3.4 & 419 & 287 \\
\hline 4 & 26.4 & Cyanidin-3-malonylglucoside & 3.0 & 535 & 287 \\
\hline 5 & 34.7 & Cyanidin-3-dioxalylglucoside & 2.0 & 593 & 287 \\
\hline \multicolumn{6}{|l|}{ Bilberry } \\
\hline 1 & 14.4 & Delphinidin-3-galactoside & 12.4 & 465 & 303 \\
\hline 2 & 17. 7 & Delphinidin-3-glucoside & 14.0 & 465 & 303 \\
\hline 3 & 20.8 & Cyanidin-3-galactoside & 9.7 & 449 & 287 \\
\hline 4 & 23.7 & Delphinidin-3-arabinoside & 8.1 & 435 & 303 \\
\hline 5 & 26.8 & Cyanidin-3-glucoside & 11.7 & 449 & 287 \\
\hline 6 & 30.9 & Petunidin-3-galactoside & 4.0 & 479 & 317 \\
\hline 7 & 33.5 & Cyanidin-3-arabinoside & 6.3 & 419 & 287 \\
\hline 8 & 38.0 & Petunidin-3-glucoside & 9.4 & 479 & 317 \\
\hline 9 & 40.8 & Peonidin-3-galactoside & 1.2 & 463 & 301 \\
\hline 10 & 44.9 & Petunidin-3-arabinoside & 2.1 & 449 & 317 \\
\hline 11 & 47.7 & Peonidin-3-glucoside & 5.4 & 463 & 301 \\
\hline 12 & 49.7 & Malvidin-3-galactoside & 3.3 & 493 & 331 \\
\hline 13 & 51.5 & Delphinidin & 0.2 & 303 & 303 \\
\hline 14 & 53.1 & Peonidin-3-arabinoside & 0.4 & 433 & 301 \\
\hline 15 & 55.1 & Malvidin-3-glucoside & 9.8 & 493 & 331 \\
\hline 16 & 58.4 & Not identified & 0.1 & - & - \\
\hline 17 & 60.9 & Malvidin-3-arabinoside & 1.6 & 463 & 331 \\
\hline 18 & 68.4 & Cyanidin & 0.3 & 287 & 287 \\
\hline \multicolumn{6}{|c|}{ Black currants } \\
\hline 1 & 6.8 & Delphinidin-3-glucoside & 19.2 & 465 & 303 \\
\hline 2 & 7.4 & Delphinidin-3-rutinoside & 40.8 & 611 & 465,303 \\
\hline 3 & 9.5 & Cyanidin-3-glucoside & 7.0 & 449 & 287 \\
\hline 4 & 10.9 & Cyanidin-3-rutinoside & 32.1 & 595 & 449,287 \\
\hline 5 & 13.4 & Not identified & 0.4 & - & - \\
\hline 6 & 16.5 & Pelargonidin-3-rutinoside & 0.3 & 579 & 433,271 \\
\hline 7 & 19.7 & Not identified & 0.2 & - & - \\
\hline \multicolumn{6}{|c|}{ Red currants } \\
\hline 1 & 6.8 & Delphinidin-3-glucoside & 0.2 & 465 & 303 \\
\hline 2 & 7.4 & Delphinidin-3-rutinoside & 0.6 & 611 & 465,303 \\
\hline 3 & 8.6 & Cyanidin-3-sambubioside & 29.1 & 581 & 287 \\
\hline 4 & 9.1 & Cyanidin-3-xylosylrutinoside & 55.4 & 727 & 581,287 \\
\hline 5 & 10.9 & Cyanidin-3-rutinoside & 14.7 & 595 & 449,287 \\
\hline
\end{tabular}

(a) \% of total anthocyanins was estimated based on $\%$ of peak area related to total area of detected anthocyanin peaks. 
cyanidin-3-sambubioside (peak 4, $54 \%,[\mathrm{M}]^{+}$at $\mathrm{m} / \mathrm{z}$ 581) and cyanidin-3-glucoside (peak 5, $31.5 \%$ ). Similar results have been reported by Veberic et al. ${ }^{[41]}$ In black mulberry extract only three components: cyanidin-3-glucoside (peak 1; $78 \%$ ), cyanidin-3-rutinoside (peak 2; $20 \%$ ) and pelargonidin-3-glucoside (peak $3 ; 1.5 \%$ ) were detected as in our previous study. ${ }^{[31]}$ These results were confirmed by MS analysis and data presented by other authors. ${ }^{[22,43]}$ Blackberry extract contains large amount of cyanidin-3-glucoside (peak 2; $91 \%$ ), which is also confirmed by other studies. ${ }^{[31,35,44,45]}$ The bilberry extract showed a large diversity of anthocyanins and some anthocyanidins as also reported by many authors. ${ }^{[46-48]}$ Eighteen compounds were detected at $520 \mathrm{~nm}$ in Romanian wild bilberry with some small differences in composition compared to our previous study. ${ }^{[31]}$ It was found high content of delphinidin-3-glucoside (peak 2; $14 \%$ ), delphinidin-3-galactoside (peak 1; $12 \%$ ) and cyanidin-3-glucoside (peak 5; $12 \%$ ). The main anthocyanins tentatively identified in black currants extract were delphinidin-3-glucoside (peak $1 ; 19 \%$; $[\mathrm{M}]^{+}$at $\mathrm{m} / \mathrm{z} 465$ ), delphinidin-3-rutinoside (peak 2; $41 \%$; [M] $]^{+}$at $\mathrm{m} / \mathrm{z} 611$ ), cyanidin-3-glucoside (peak 3; $7 \%$ ), and cyanidin-3-rutinoside (peak 4; $32 \%$ ). Our results are in agreement with other studies that have reported the same major anthocyanins in black currants. ${ }^{[16,49-51]}$ In red currants extract, the major anthocyanins tentatively identified were cyanidin-3-sambubioside (peak 3; $29 \%$; [M] $]^{+}$at $m / z 581$ ), cyanidin-3-xylosylrutinoside (peak 4; $55 \%$; [M] ${ }^{+}$at $m / z$ 727), and cyanidin-3rutinoside (peak $5 ; 15 \%$ ) in accordance with Borges et al. ${ }^{[51]}$

The results regarding the contents of monomeric anthocyanins (AC) and total phenolics content (TPC) in the selected fruits varies considerably. Significant differences in anthocyanins content between fruits extracts were recorded $(p<0.05)$. The monomeric anthocyanins content in the fruits extracts expressed as cyanidin-3-glucoside ranged from $68 \pm 0.2 \mathrm{mg} \mathrm{L}^{-1}$ to $4976 \pm 22.6 \mathrm{mg} \mathrm{L}^{-1}$ (Table 2). The highest content of monomeric anthocyanins was found in the elderberry extract $(4976 \pm 22.6)$ followed by black currant extract ( $4864 \pm 3.2 \mathrm{mg} \mathrm{L}^{-1}$ ) and bilberry extract (3286 \pm $\left.3.9 \mathrm{mg} \mathrm{L}^{-1}\right)$, whereas the anthocyanin content in strawberry (387 $\left.\pm 0.9 \mathrm{mg} \mathrm{L}^{-1}\right)$, raspberry $\left(107 \pm 0.0 \mathrm{mg} \mathrm{L}^{-1}\right)$ and red currant extracts ( $68 \pm 0.2 \mathrm{mg} \mathrm{L}^{-1}$ ) were significantly lower. High content of anthocyanins in elderberry compared to other fruits was also reported by other authors. ${ }^{[35,52]}$

Total phenolics content in selected fruits extracts varied from $961 \pm 6.6 \mathrm{mg} \mathrm{GAE} \mathrm{L}^{-1}$ to $7735 \pm 37.3 \mathrm{mg} \mathrm{GAE} \mathrm{L}^{-1}$ (Table 2). Significantly higher content of total phenolics was observed for elderberry ( $\left.7735 \pm 37.3 \mathrm{mg} \mathrm{GAE} \mathrm{L}^{-1}\right)$ and black currant $\left(6241 \pm 56.2 \mathrm{mg} \mathrm{GAE} \mathrm{L}^{-1}\right)$ extracts. Red currant extract shows the lowest content of total phenolics (961 \pm $6.6 \mathrm{mg} \mathrm{GAE} \mathrm{L}^{-1}$ ), as was also previously reported by other authors. ${ }^{[53]}$ Our results showed that most of the studied fruits but especially elderberries, black currants and bilberry are good sources of phenolic compounds including anthocyanins. Anthocyanins were the predominant phenolic subgroup in black currant, bilberry and elderberry extract, their proportion of total phenols content exceeding $60 \%$. In order to evaluate antioxidant activity of the selected fruits extracts three classical methods (DPPH, ABTS and FRAP) based on reaction between antioxidants and a chromogen compound were chosen. We also tried to use an electrochemical method, cyclic voltammetry, for estimation of overall reducing capacity of fruits extracts.

Overall, the values obtained for antioxidant activities by ABTS and FRAP assays for studied fruit extracts are relatively close, while the results obtained by DPPH assay are generally much lower with one exception: red currant extract (Table 2). Although values obtained for antioxidant activity by the three classical methods are different, however it can be observed the same general tendency. Therefore, the following order of antioxidant activities of the fruits extracts was established: elderberry $>$ black currant $>$

Table 2. Identification of anthocyanins form studied fruits extracts.

\begin{tabular}{|c|c|c|c|c|c|c|}
\hline \multirow{2}{*}{ No. } & \multirow{2}{*}{ Extract } & \multirow{2}{*}{$\mathrm{TAC} / \mathrm{mg} \mathrm{L}^{-1}$} & \multirow{2}{*}{$\mathrm{TPC} / \mathrm{mg} \mathrm{GAE} \mathrm{L^{-1 }}$} & \multicolumn{3}{|c|}{ Antioxidant activity / mmol L-1 Trolox Eq. } \\
\hline & & & & DPPH & ABTS & FRAP \\
\hline 1. & Strawberry & $387 \pm 0.9$ & $1849 \pm 23.5$ & $9.4 \pm 0.0^{\mathrm{a}}$ & $20.9 \pm 1.58^{a}$ & $11.4 \pm 0.4$ \\
\hline 2. & Raspberry & $107 \pm 0.0$ & $1099 \pm 5.9$ & $6.1 \pm 0.1^{c}$ & $9.5 \pm 0.14^{b c}$ & $9.5 \pm 0.1$ \\
\hline 3. & Elderberry & $4976 \pm 22.6$ & $7735 \pm 37.3$ & $31.7 \pm 0.7$ & $74.0 \pm 2.1^{d}$ & $63.1 \pm 0.7$ \\
\hline 4. & Mulberry & $1200 \pm 3.8$ & $2326 \pm 3.2$ & $9.1 \pm 0.2^{\mathrm{a}}$ & $15.9 \pm 0.3^{\mathrm{ab}}$ & $14.9 \pm 0.3$ \\
\hline 5. & Blackberry & $1346 \pm 2.6$ & $3300 \pm 32.7$ & $17.7 \pm 0.6$ & $35.3 \pm 3.6$ & $28.1 \pm 0.9$ \\
\hline 6. & Bilberry & $3286 \pm 3.9$ & $4636 \pm 13.4$ & $22.5 \pm 0.4^{b}$ & $44.6 \pm 0.5$ & $40.7 \pm 0.2$ \\
\hline 7. & Black currant & $4864 \pm 3.2$ & $6241 \pm 56.2$ & $22.6 \pm 0.3^{b}$ & $67.3 \pm 2.5^{d}$ & $58.1 \pm 0.7$ \\
\hline 8. & Red currant & $68 \pm 0.2$ & $961 \pm 6.6$ & $5.1 \pm 0.3^{c}$ & $4.9 \pm 1.1^{c}$ & $5.0 \pm 0.3$ \\
\hline
\end{tabular}

All data are expressed as means of three replication \pm SD. The values followed by the same letter are not significantly different $(p>0.05)$. 
bilberries > blackberries > strawberry > mulberry > raspberry $>$ red currants, based on DPPH and ABTS assays. By FRAP assay the order of antioxidant activity is almost the same, only mulberry and strawberry are inversely ordered. Among the selected fruits, elderberries are distinguished by an exceptional antioxidant activity $(31.7 \pm 0.7,74.0 \pm 2.1$ and $63.1 \pm 0.7 \mathrm{mmol} \mathrm{L}^{-1}$ Trolox eq. as determined by the DPPH, ABTS, and FRAP assay, respectively), followed by black currant extract $(22.6 \pm 0.3,67.3 \pm 2.5$ and $58.1 \pm$ $0.7 \mathrm{mmol} \mathrm{L}^{-1}$ Trolox eq. as determined by the DPPH, ABTS, and FRAP assay, respectively). Our results are in agreement with other studies indicating black currants and elderberries as having strong antioxidant activities. ${ }^{[16,35]}$ However, both antioxidant activities and the content of anthocyanins and total phenolics of fruits may be influenced by degree of ripeness, cultivars, climate or growing condition, ${ }^{[54-56]}$ so the results reported by various authors can be quite different.

The relationships between the antioxidant activities evaluated by DPPH, ABTS, and FRAP and the content of monomeric anthocyanins and total phenolics are shown in Figure 2 and Figure 3, respectively. Good correlation were obtained between antioxidant activities and total phenolics content, determination coefficients $\left(R^{2}\right)$ were greater than 0.95 indicating that phenolic compounds play a major role on the antioxidant capacities of selected fruits extracts. Lower values for determination coefficients were obtained for antioxidant activity versus anthocyanins content $\left(R^{2}>\right.$ $0.8773)$. Antioxidant activities evaluated by FRAP assay are better correlated with total phenolics content $\left(R^{2}=0.9825\right)$ and anthocyanin content $\left(R^{2}=0.9753\right)$ than the other two methods.

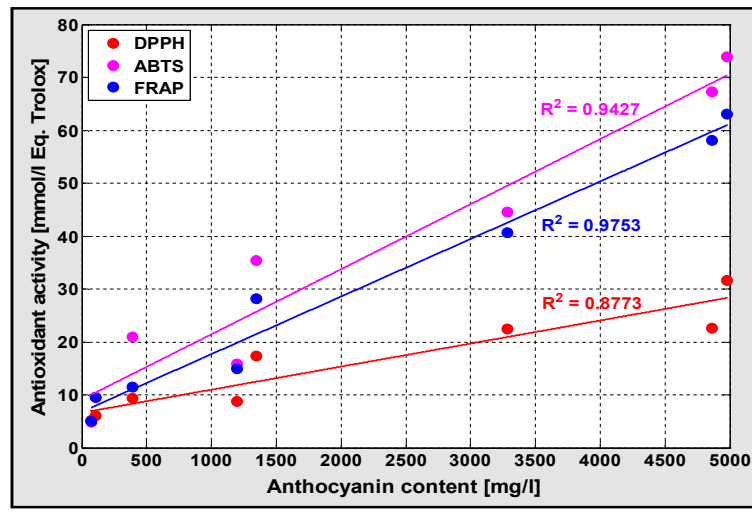

Figure 2. Correlation between antioxidant activity and anthocyanins content.

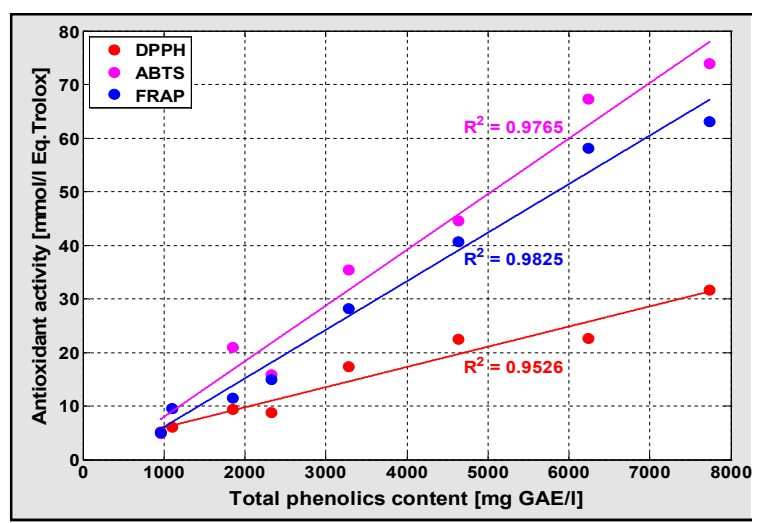

Figure 3. Correlation between antioxidant activity and total phenolics content.

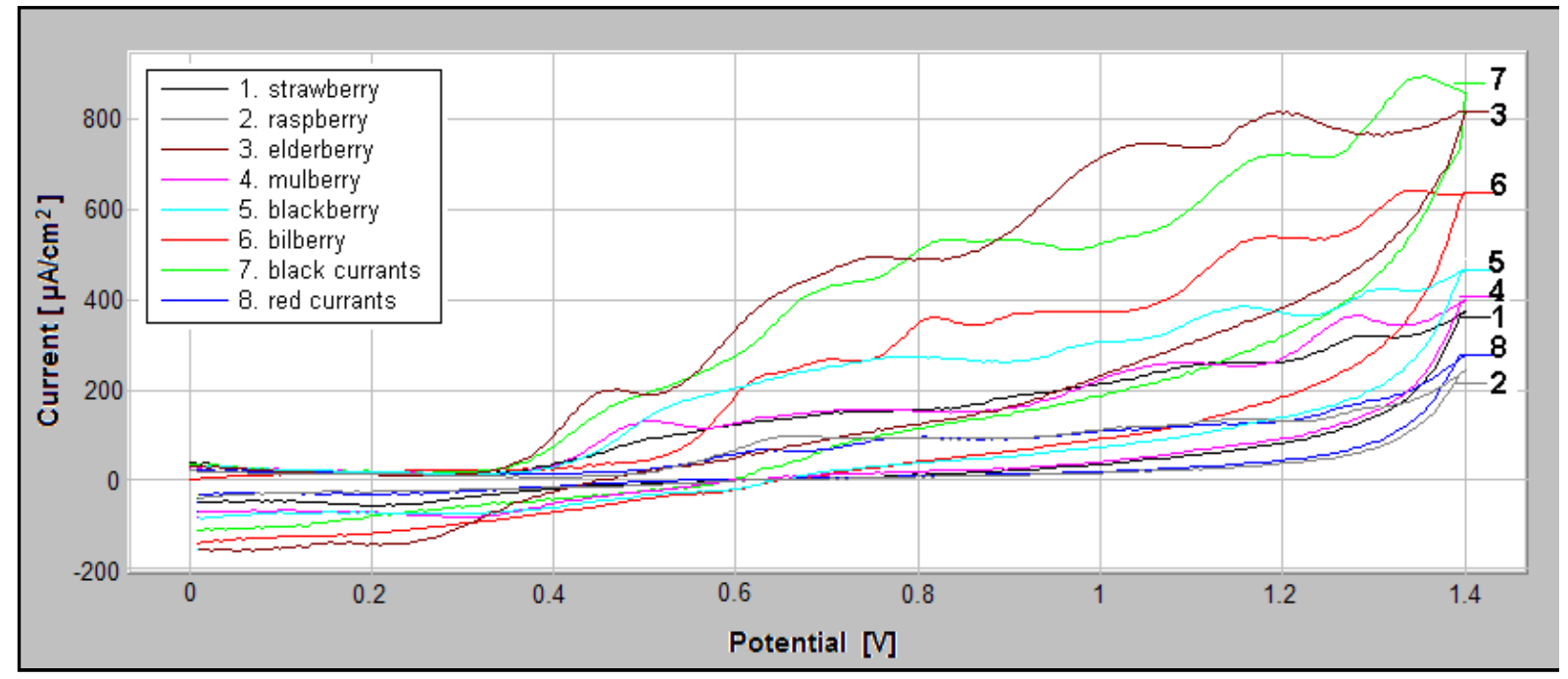

Figure 4. Cyclic voltammograms of fruit extracts using $\mathrm{NaClO}_{4} 0.1 \mathrm{M}$ in methanol as supporting electrolyte (background subtracted). 
Table 3. Electrochemical parameters $\left(E_{1 / 2}, l_{\mathrm{a}}, S_{\mathrm{a}}\right)$ and total electrochemical reducing power (TERP) for fruits extracts.

\begin{tabular}{|c|c|c|c|c|c|}
\hline No. & Extract & $E_{1 / 2} / \mathrm{mV}$ & $l_{\mathrm{a}} / \mu \mathrm{A} \mathrm{cm} \mathrm{cm}^{-2}$ & $S_{\mathrm{a}} / \mu \mathrm{W} \mathrm{cm}^{-2}$ & TERP / mmol L ${ }^{-1}$ Trolox Eq. \\
\hline 1. & Strawberry & $477.6 \pm 1.5$ & $153.6 \pm 1.3$ & $173.7 \pm 0.4^{(\mathrm{a})}$ & $20.9 \pm 0.1^{(a)}$ \\
\hline 2. & Raspberry & $573.5 \pm 1.3^{(\mathrm{a})}$ & $99.4 \pm 1.1$ & $86.3 \pm 0.7^{(b)}$ & $8.4 \pm 0.1^{(b)}$ \\
\hline 3. & Elderberry & $400.5 \pm 1.5^{(b)}$ & $201.2 \pm 2.1$ & $484.9 \pm 2.8$ & $65.6 \pm 0.4$ \\
\hline 4. & Mulberry & $435.5 \pm 1.5$ & $130.5 \pm 2.2$ & $180.6 \pm 0.1^{(\mathrm{a})}$ & $21.9 \pm 0.0^{(a)}$ \\
\hline 5. & Blackberry & $468.4 \pm 1.4$ & $185.8 \pm 1.6^{(\mathrm{a})}$ & $261.9 \pm 1.5$ & $33.6 \pm 0.2$ \\
\hline 6. & Bilberry & $569.3 \pm 1.5^{(\mathrm{a})}$ & $234.3 \pm 2.4$ & $336.5 \pm 2.8$ & $44.3 \pm 0.4$ \\
\hline 7. & Black currant & $401.0 \pm 1.9^{(b)}$ & $189.9 \pm 2.8^{(a)}$ & $509.3 \pm 5.3$ & $69.1 \pm 0.8$ \\
\hline 8. & Red currant & $534.6 \pm 4.0$ & $66.9 \pm 1.2$ & $82.4 \pm 1.6^{(b)}$ & $7.8 \pm 0.2^{(b)}$ \\
\hline
\end{tabular}

The electrochemical behavior of the fruits extracts was investigated using a glassy carbon electrode (GCE) in $\mathrm{NaClO}_{4} 0.1 \mathrm{M}$ in methanol $(\mathrm{pH} 3)$ as supporting electrolyte. Glassy carbon is considered an excellent electrode material for the study of natural antioxidants. ${ }^{[57]}$ The reducing capacity of a sample can be analyzed by three parameters: the oxidation potentials characterized by $E_{1 / 2}$ value, the anodic peak current $\left(I_{\mathrm{a}}\right)$ and the area under the anodic wave $\left(S_{\mathrm{a}}\right)$. $E_{1 / 2}$ reflects the specific reducing power of a component or more components with similar potential, while $I_{\mathrm{a}}$ and $S_{\mathrm{a}}$ are related to the concentration of antioxidants. ${ }^{[58,59]}$

The cyclic voltammograms (Figure 4) were recorded at the scan rate $500 \mathrm{mV} \mathrm{s}^{-1}$, in the range $0-1400 \mathrm{mV}$. In order to highlight the oxidation processes more clearly, ${ }^{[21]}$ the cyclic voltammograms of supporting electrolyte were subtracted from the cyclic voltammograms of the extracts (Figure 4). The cyclic voltammograms shapes are quite different from one fruit extract to another and display many oxidation peaks. Reducing capacity of selected fruits extracts was assessed based on the half-peak potential $\left(E_{1 / 2}\right)$ of the first oxidation peak and on the area under anodic curve (Table 3 ). The position of anodic peaks in the voltammograms suggests the antioxidant ability; peaks at lower potential mean a higher antioxidant capacity. ${ }^{[58]}$

The reducing capacities of the studied extracts based on the values of $E_{1 / 2}$ for voltammetric curves recorded in $\mathrm{NaClO}_{4} 0.1 \mathrm{M}$ in methanol decrease in the following order: elderberry $>$ black currant $>$ mulberry $>$ blackberry $>$ strawberry $>$ red currants $>$ raspberry $>$ bilberry. The results obtained by cyclic voltammetry are very different from those obtained by conventional analytical methods for determining the antioxidant activity. There is no correlation between oxidation potentials characterized by $E_{1 / 2}$ value and antioxidant activities evaluated by the three classical methods, determination coefficients $R^{2}$ ranging from 0.2565 to 0.3833 . There are several studies carried out on

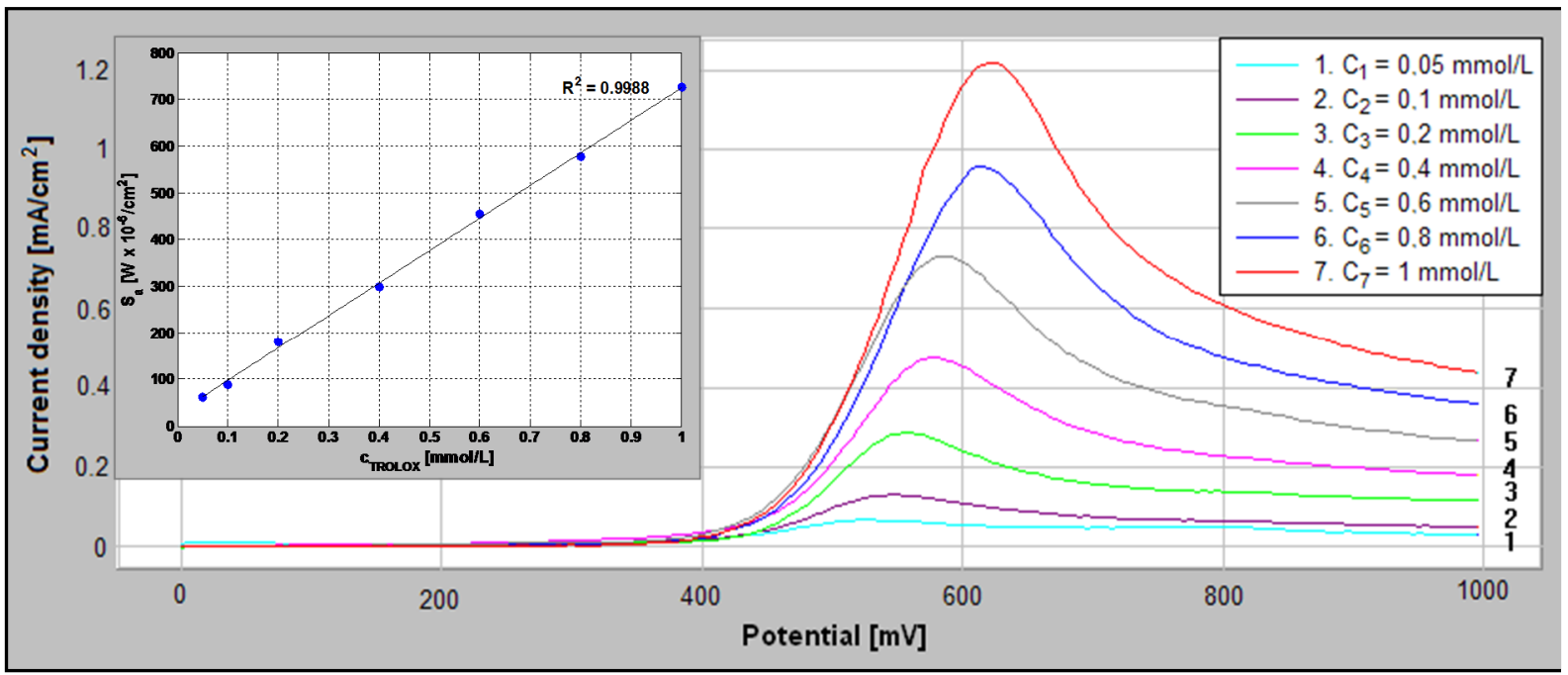

Figure 5. Cyclic voltammograms of Trolox using $\mathrm{NaClO} 40.1 \mathrm{M}$ in methanol as supporting electrolyte (background subtracted) and calibration curve of area under the anodic curve $\left(S_{a}\right)$ versus concentration of Trolox solution ( $C_{\text {TROLOX }}$ ). 
pure compounds that have shown that oxidation potential is highly dependent on phenolic compound structure and there is a correlation between oxidation potential and antioxidant activity measured by a classical method. ${ }^{[60-62]}$ But in our case, that of complex mixtures, this approach to assess the reducing ability of the extracts based on $E_{1 / 2}$ value of the first oxidation peak has proven to be inappropriate.

According to other researchers, ${ }^{[63]}$ the area under the anodic curves $\left(S_{a}\right)$ can express better the total reducing power of complex mixtures of antioxidant compounds like plant extracts. Each peak of anodic curve reflects a component or a combination of components that donate electrons at about the same potential. In order to achieve a proper correlation of electrochemical results with antioxidant activities determined by classical methods (DPPH, $A B T S$, and FRAP), we converted the area under the anodic curves $\left(S_{\mathrm{a}}\right)$ to Trolox equivalents based on the calibration curve. In Figure 5 are presented the cyclic voltammograms for Trolox solution and the calibration curve representing the area under the anodic curve versus concentration of Trolox solution.

For all extracts we expressed the total electrochemical reducing power (TERP) as $\mathrm{mmol}^{-1}$ Trolox equivalents. The reducing capacities of the studied extracts based on the values of $S_{a}$ decrease in the following order: black currant $>$ elderberry $>$ bilberry $>$ blackberry $>$ mulberry $>$ strawberry $>$ raspberry $>$ red currants. The results obtained by cyclic voltammetry related to $S_{\mathrm{a}}$ are a little different from those obtained by conventional methods but neither chemical methods, nor electrochemical methods provide absolute results. However, good correlation for TERP versus total phenolics content $\left(R^{2}=0.9552\right)$ and TERP versus anthocyanin content $\left(R^{2}=0.9625\right)$ were obtained. Also, good correlations ( $R^{2}$ ranging from 0.8823 to 0.9798 ) were observed between the results regarding antioxidant capacity

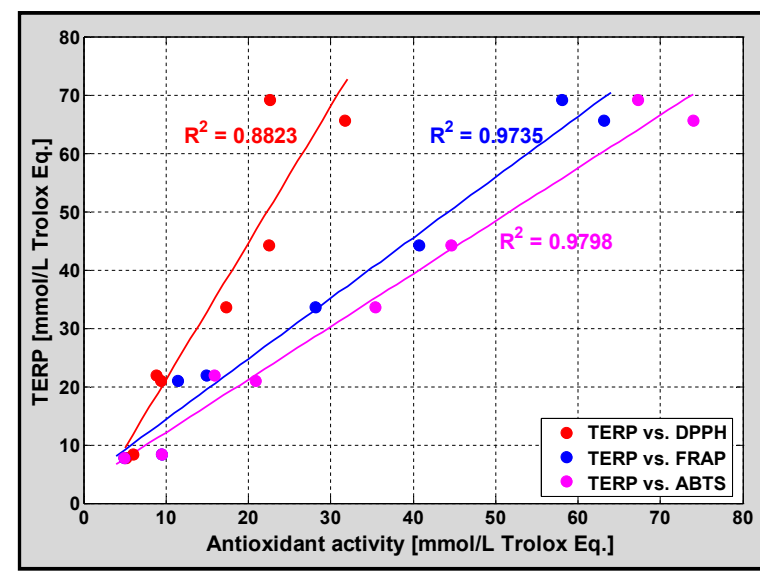

Figure 6. Correlation between total electrochemical reducing power (TERP) and antioxidant activities assessed by conventional methods (DPPH, FRAP, ABTS). assessed by cyclic voltammetry $\left(S_{a}\right)$ and those obtained through the three conventional assays (Figure 6). Cyclic voltammetry proved to be a rapid and simple technique to evaluate the antioxidant properties of natural extracts with complex composition.

\section{CONCLUSIONS}

In this study eight selected fruits were examined for their antioxidant properties, anthocyanins and total phenolics content. The results showed that the anthocyanin content and composition, total phenolics content and antioxidant activities of the selected fruits varied considerably. Some of analyzed fruits native from Banat County, Romania such as elderberry, black currants or bilberry are extremely rich sources of anthocyanins and other phenolic compounds and also possess great antioxidant activities. This work brings together two types of methods (chemical and electrochemical) in order to characterize the antioxidant abilities of some indigenous fruit extracts. Despite the fact that the fruits belong to different botanical families, very good correlations were obtained especially between total phenolics content and antioxidant activity estimated by classical chemical methods (DPPH, ABTS, FRAP). Also, the evaluation of total electrochemical reducing power (TERP) of fruit extracts through cyclic voltammetry based on the area under the anodic curves led to surprisingly good results. The results obtained in this work are encouraging for evaluation of antioxidant activity of complex mixtures of natural antioxidants by cyclic voltammetry. Compared to conventional methods, this technique is simple, fast, inexpensive and reliable for colored samples.

Acknowledgment. This work is part of the project no. 52145 / 2008 - "Hypoglycemic and antioxidant dietary supplements with anthocyanidinic structure - SAHASA", carried out under the Executive Unit for Financing Higher Education, Research, Development and Innovation (UEFISCDI) - the $4^{\text {th }}$ Programme - Partnerships in priority areas of The National Plan for Research-Development and Innovation 2007-2013 (Romania).

\section{REFERENCES}

[1] $\varnothing$. M. Andersen, M. Jordheim in: Flavonoids: Chemistry, biochemistry and applications (Eds. $\emptyset$. M. Andersen, K. R. Markham), CRC Press, Taylor \& Francis Group, Boca Raton, USA, 2006, pp. 471-552.

[2] J. M. Kong, L. S. Chia, N. K. Goh, T. F. Chia, R. Brouillard, Phytochem. 2003, 64, 923.

[3] J. He, M. M. Giusti, Annu. Rev. Food Sci. Technol. 2010, 1, 163.

[4] M. N. Lila, J. Biomed. Biotechnol. 2004, 5, 306. 
[5] D. Ghosh, T. Konishi, Asia. Pac. J. Clin. Nutr. 2007, 16, 200.

[6] D. R. Bell, K. Gochenaur, J. Appl. Physiol. 2006, 100, 1164.

[7] G. Mazza, Ann. I. Super. Sanita. 2007, 43, 369.

[8] T. C. Wallace, Adv. Nutr. 2011, 2, 1.

[9] T. Borkowski, H. Szymusiak, A. Gliszczyńska-Swigło, B. Tyrakowska, Food Res. Int. 2005, 38, 1031.

[10] A. Castañeda-Ovando, Ma. de Lourdes PachecoHernández, Ma. E. Páez-Hernández, J. A. Rodríguez, and C. A. Galán-Vidal, Food Chem. 2009, 113, 859.

[11] Q. Tian, M. M. Giusti, G. D. Stoner, S. J. Schwartz, J. Chromatogr. A. 2005, 1091, 72.

[12] J. S. Barnes, H. P. Nguyen, S. Shen, K. A. Schug, J. Chromatogr. A. 2009, 1216, 4728.

[13] G. A. Garzón, C. E. Narváez, K. M. Riedl, S. J. Schwartz, Food Chem. 2010, 122, 980.

[14] W. Mullen, S. Larcombe, K. Arnold, H. Welchman, A. Crozier, J. Agric. Food Chem. 2010, 58, 3910.

[15] M. P. Kähkönen, J. Heinämäki, V. Ollilainen, M. Heinonen, J. Sci. Food Agr. 2003, 83, 1403.

[16] X. Wu, L. Gu, R. L. Prior, S. McKay, J. Agric. Food Chem. 2004, 52, 7846.

[17] L. Jakobek, M. Seruga, Int. J. Food Prop. 2012, 15, 122.

[18] N. Pellegrini, M. Serafini, B. Colombi, D. Del Rio, S. Salvatore, M. Bianchi, F. Brighenti, J. Nutr. 2003, 133, 2812.

[19] D. Huang, B. Ou, R. L. Prior, J. Agric. Food Chem. 2005, 53, 1841.

[20] J. S. Wright, E. R. Johnson, G. A. DiLabio, J. Am. Chem. Soc. 2001, 123, 1173.

[21] J. -B. He, S. -J. Yuan, J. -Q. Du, X. -R. Hu, Y. Wang, Bioelectrochem. 2009, 75, 110.

[22] D. H. S. Silva, F. C. Pereira, M. Yoshida, M. V. B. Zanoni, Ecl. Quím. 2005, 30, 15.

[23] A. Simić, D. Manojlović, D. Šegan, M. Todorović, Molecules 2007, 12, 2327.

[24] M. S. Cosio, S. Buratti, S. Mannino, S. Benedetti, Food Chem. 2006, 97, 725.

[25] L. Barros, L. Cabrita, M. V. Boas, A. M. Carvalho, I. C. F. R. Ferreira, Food Chem. 2001, 127, 1600.

[26] A. Pekal, P. Drozdz, K. Pyrzynska, Int. J. Food Prop. 2012, 15, 1101.

[27] P. A. Kilmartin, H. Zou, A. L. Waterhouse, J. Agric. Food Chem. 2001, 49, 1957.

[28] O. Makhotkina, P. A. Kilmartin, Anal. Chim. Acta 2010, 668, 155.

[29] M. M. Giusti, R. E. Wrolstadin: Current Protocols in Food Analytical Chemistry, John Wiley \& Sons, New York, USA, 2001, pp. F1.2.1-F1.2.13.

[30] A. L. Waterhouse in: Current Protocols in Food Analytical Chemistry, John Wiley \& Sons, New York, USA, 2002, pp. |1.1.1-|1.1.8.
[31] M. N. Ştefănuţ, A. Căta, R. Pop, C. Moşoarcă, A. D. Zamfir, Anal. Lett. 2011, 44, 2843.

[32] W. Brand-Williams, M. E. Cuvelier, C. Berset, LWT Food Sci. Technol. 1995, 28, 25.

[33] I. F. F. Benzie, J. J. Strain, Anal. Biochem. 1996, 239, 70.

[34] M. Ozgen, R. N. Reese, A. Z. Tulio Jr., J. C. Scheerens, R. Miller, J. Agric. Food Chem. 2006, 54, 1151.

[35] L. Jakobek, M. Šeruga, M. Medvidović-Kosanović, I. Novak, Dtsch. Lebensm. Rundsch. 2007, 103, 58.

[36] F. Lopes-da-Silva, S. de Pascual-Teresa, J. RivasGonzalo, C. Santos-Buelga, Eur. Food Res. Technol. 2002, 214, 248.

[37] A. B. Cerezo, E. Cuevas, P. Winterhalter, M. C. GarciaParrilla, A. M. Troncoso, Food Chem. 2010, 103, 574.

[38] B. de Ancos, E. Gonzalez, and M. P. Cano, Z. Lebensm. Unters. Forsch. A 1999, 208, 33.

[39] W. Mullen, J. McGinn, M. E. J. Lean, M. R. MacLean, P. Gardner, G. G. Duthie, T. Yokota, A. Crozier, J. Agric. Food Chem. 2002, 50, 5191.

[40] F. Chen, Y. Sun, G. Zhao, X. Liao, X. Hu, J. Wu, Z. Wang, Ultrason. Sonochem. 2007, 14, 767.

[41] R. Veberic, J. Jakopic, F. Stampar, V. Schmitzer, Food Chem. 2009, 114, 511.

[42] P. Dugo, L. Mondello, G. Errante, G. Zappia, G. Dogo, J. Agric. Food Chem. 2001, 49, 3987.

[43] A. M. Pawlowska, W. Oleszek, A. Braca, J. Agric. Food Chem. 2008, 56, 3377.

[44] I. Elisia, C. Hu, D. G. Popovich, D. D. Kitts, Food Chem. 2007, 101, 1052.

[45] L. Jakobek, M. Šeruga, B. Šeruga, I. Novak, M. Medvidović-Kosanović, Int. J. Food Sci. Tech. 2009, 44, 860.

[46] Z. Zhang, X. Kou, K. Fugal, J. McLaughlin, J. Agric. Food Chem. 2004, 52, 688.

[47] T. Ichiyanagi, Y. Hatano, S. Matsugo, T. Konishi, Chem. Pharm. Bull. 2004, 52, 628.

[48] C. Cassinese, E. de Combarieu, M. Falzoni, N. Fuzzati, R. Pace, N. Sardone, J. AOAC Int. 2007, 90, 911.

[49] M. P. Kähkönen, A. I. Hopia, M. Heinonen, J. Sci. Food Agr. 2001, 49, 4076.

[50] M. Rubinskiene, I. Jasutiene, P. R. Venskutonis, P. Viskelis, J. Chromatogr. Sci. 2005, 43, 478.

[51] G. Borges, A. Degeneve, W. Mullen, A. Crozier, J. Agric. Food Chem. 2010, 58, 3901.

[52] Z. Rimpapa, J. Toromanović, I. Tahirović, A. Sapcanin, E. Sofić, Bosn. J. Basic. Med. Sci. 2007, 7, 117.

[53] G. E. Pantelidis, M. Vasilakakis, G. A. Manganaris, Gr. Diamantidis, Food Chem. 2007, 102, 777.

[54] A. M. Connor, J. J. Luby, C. B. S. Tong, C. E. Finn, J. F. Hancock, J. Am. Soc. Hortic. Sci. 2002, 127, 89.

[55] T. Siriwoharn, R. E. Wrolstad, C. E. Finn, C. B. Pereira, J. Agric. Food Chem. 2004, 52, 8021. 
[56] M. Rubinskiene, P. Viskelis, I. Jasutiene, R. Viskeliene, C. Bobinas, Food Res. Int. 2005, 38, 867.

[57] P. A. Kilmartin, Antioxid. Redox Sign. 2001, 3, 941.

[58] S. Chevion, M. A. Roberts, M. Chevion, Free Radical. Bio. Med. 200o, 28, 860.

[59] L. M. Magalhães, M. A. Segundo, S. Reis, J. L. F. C. Lima, Anal. Chim. Acta 2008, 613, 1.

[60] B. Yang, A. Kotani, K. Arai, F. Kusu, Anal. Sci. 2001,
17, 599.

[61] A. A. De Lima, E. M. Sussuchi, W. F. de Giovani, Croat. Chem. Acta 2007, 80, 29.

[62] K. E. Yakovleva, S. A. Kurzeev, E. V. Stepanova, T. V. Fedorova, B. A. Kuznetsov, O. V. Koroleva, Appl. Biochem. Microbiol. 2007, 43, 661.

[63] S. Chevion, M. Chevion, B. Chock, G. R. Beecher, J. Med. Food. 1999, 1, 1. 